SMAD, Rev Eletrônica Saúde Mental Álcool Drog.

2021 abr.-jun.;17(2):1-3

DOI: 10.11606/issn.1806-6976.smad.2021.000176

www.revistas.usp.br/smad/

Apresentação

\title{
Identificação de demandas e caminhos para o cuidado em saúde mental entre diferentes populações e em tempos de crise
}

Ana Carolina Guidorizzi Zanetti ${ }^{1}$

(iD) http://orcid.org/000-0003-0011-4510

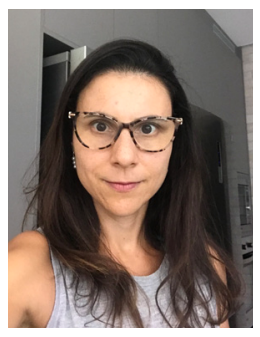

Reconhece-se cada vez mais a importância da divulgação da produção científica na área de Saúde Mental, em especial, frente à epidemia causada pela síndrome respiratória aguda grave do coronavírus 2 (SARS-CoV-2). Esse fascículo expressa a busca dos pesquisadores quanto aos recursos de enfrentamento baseado em evidências científicas para auxiliar os estudantes e a equipe de Enfermagem no entendimento das demandas de cuidado e agregar novos conhecimentos a prática clínica.

O editorial, de autoria de Andrés Eduardo Aguirre Antúnez, Professor Livre-Docente do Departamento de Psicologia Cínica da Universidade de São Paulo (USP) e Coordenador do Escritório de Saúde Mental vinculado à Pró-Reitoria de Graduação da USP, discute sobre as consequências da pandemia em relação a saúde mental das pessoas e, principalmente, daquelas que já apresentavam algum transtorno mental anteriormente, destacando a importância de um cuidado que considere a ética, empatia e compaixão. Além disso, reflete sobre ações que podem ser desenvolvidas para o cuidado em saúde mental e relata sobre experiências realizadas com estudantes e funcionários de uma instituição de ensino superior durante a pandemia.

No artigo denominado: Distanciamento social e COVID-19: estratégias adotadas por estudantes de Enfermagem, os leitores terão a oportunidade de conhecer as estratégias adotadas por 148 estudantes de Enfermagem, no Brasil, para o enfrentamento da doença por meio do distanciamento social durante a pandemia da COVID-19. Os resultados desse estudo ressaltam a importância de considerar a orientação aos estudantes por profissionais qualificados e a contribuição das instituições universitárias na estruturação de ações de Saúde Mental aos estudantes.

Ainda, em relação à população alvo graduandos da área da saúde, o estudo sobre Uso de substâncias lícitas entre os estudantes de Fonoaudiologia de uma universidade pública mostra o consumo de álcool e tabaco de estudantes da Área de Fonoaudiologia. Ao considerar que o uso dessas substâncias é agressivo

\footnotetext{
1 Universidade de São Paulo, Escola de Enfermagem de Ribeirão Preto, Centro Colaborador da OPAS/OMS para o Desenvolvimento da Pesquisa em Enfermagem, Ribeirão Preto, SP, Brasil.
}

\section{Como citar este artigo}

Zanetti ACG. Identification of demands and paths for mental health care among different populations and in times of crisis. SMAD, Rev Eletrônica Saúde Mental Álcool Drog. 2021 abr.-jun.;17(2):1-3. doi: https://dx.doi.org/10.11606/issn.1806-6976.smad.2021.000176. 
ao mecanismo vocal, os autores ressaltam que o conhecimento das possíveis alterações causadas pelo uso das substâncias lícitas é importante aos futuros profissionais para obtenção de ações exitosas sobre noções básicas de saúde à comunidade

O artigo Satisfação, sobrecarga e opinião sobre doença mental de profissionais de saúde traz a sua contribuição para o avanço do conhecimento ao investigar a atitude, satisfação e sobrecarga de 46 profissionais das equipes da Rede de Atenção Psicossocial de uma cidade no norte do Paraná. Esse estudo nos leva a refletir sobre a importância da qualidade dos serviços de saúde mental por meio da capacitação, aprimoramento, educação continuada e infraestrutura que favoreça condições e organização do processo de trabalho adequado aos profissionais da área de saúde mental.

$O$ artigo Bem-estar mental de enfermeiros em um hospital de urgência e emergência analisa a autopercepção dos enfermeiros sobre os fatores que interferem no bem-estar mental durante o processo de trabalho em um hospital de urgência e emergência. Reconhece-se que o bem-estar mental está relacionado a uma resposta sistêmica que o corpo expressa quando submetido a determinadas situações de vida como satisfação, felicidade, anseios, doença, afeto, cognição, emoções, sentimentos, experiências e perspectivas individuais. Portanto, os enfermeiros que atuam em unidades de urgência e emergência podem estar propensos ao desgaste mental devido aos aspectos negativos relacionados a esse ambiente de trabalho. Recomenda-se melhoria das condições de trabalho e de bemestar mental dos enfermeiros.

O artigo Depressão em pacientes atendidos em serviço de saúde mental: prevalência e fatores associados identificou que fatores como insônia, risco de suicídio e pacientes do sexo feminino são preditores de depressão. Nessa direção, o estudo em tela ressalta a necessidade de identificação precoce de possíveis fatores, bem como os diagnósticos de enfermagem a fim de favorecer a implementação de cuidados efetivos a pacientes atendidos em Centro de Atenção Psicossocial.

O estudo Jogos de raciocínio como recurso terapêutico no tratamento de adolescentes dependentes de substâncias psicoativas propõe ampliar os recursos interventivos para recuperação e reabilitação do adolescente em situação de dependência de substâncias psicoativas. Os autores mostram que o impacto da aplicação de um programa por meio de jogos de raciocínio embasado na metodologia Mind Lab nas funções executivas atenção, flexibilidade e planejamento em adolescentes em situação de dependência de substâncias psicoativas melhora as funções executivas e reforçam a importância da aplicação de novas estratégias e recursos no tratamento a essa clientela.

A prevalência do transtorno depressivo maior em 183 pessoas com dependência química pertencentes a duas Comunidades Terapêuticas de Acolhimento a Dependentes Químicos, no sul de Santa Catarina, foi abordada no artigo Prevalência do transtorno depressivo maior em pessoas com dependência química. Os resultados desse estudo mostraram que a prevalência foi elevada. Os autores recomendam que estratégias terapêuticas sejam mais assertivas e eficazes.

O estudo denominado Associações entre uso de álcool e perfil sociodemográfico de universitários de Enfermagem e Nutrição, com 170 estudantes universitários mostrou que houve associação entre estudantes na faixa etária de 17 e 23 anos, idade de primeiro contato com bebida alcoólica entre 10 e 17 anos, residir com amigos com os padrões de baixo risco e nocivo para o uso de álcool. Além disso, o uso de bebidas fermentadas foi associado ao padrão de baixo risco.

Outro estudo também conduzido com graduandos de Enfermagem intitulado Fadiga e uso de álcool por graduandos do curso de Enfermagem analisou o uso de álcool no padrão binge drinking e os níveis de fadiga nessa clientela. o "binge drinking" ou "beber pesado episódico" é um padrão de consumo que expõe o indivíduo a um maior risco para danos sociais e de saúde, como prejuízos nas atividades acadêmicas e laborais, sendo comum entre os jovens. Esse estudo mostrou que 33,7\% dos participantes relataram binge drinking, e este padrão foi associado à presença de fadiga e ao desempenho acadêmico.

O último artigo Aspectos alinhados a cultura de segurança do paciente propôs uma revisão integrativa da literatura na perspectiva da segurança do paciente. Os 12 artigos analisados evidenciaram que a educação permanente, a educação em saúde e a coordenação de cuidados com o gerenciamento dos casos são fatores essenciais para garantir a segurança da pessoa com transtorno mental. Por outro lado, reconhece-se que a saúde dos profissionais e seu engajamento com o paciente sejam fatores importantes para assegurar a qualidade do atendimento prestado e a segurança do paciente.

Os artigos contribuem para o avanço do conhecimento na Área de Saúde Mental ao apontar estratégias de enfrentamento do distanciamento social e da COVID-19, uso de substâncias lícitas, padrões de consumo de álcool e fatores associados entre graduandos da área da saúde, as comorbidades associadas ao uso de substâncias, recursos 
terapêuticos possíveis e condições relacionadas aos profissionais de saúde em seu ambiente de trabalho, elementos fundamentais para a prevenção e promoção em Saúde Mental. Espera-se que o material apresentado sirva de inspiração aos leitores para sua atuação na prática clínica e desenvolvimento de futuras pesquisas em Saúde Mental.

Autor de correspondência:

Ana Carolina Guidorizzi Zanett

E-mail: carolzan@eerp.usp.br

(iD) ORCID: http://orcid.org/ 0000-0003-0011-4510
Copyright $\odot 2021$ SMAD, Rev Eletrônica Saúde Mental Álcool Drog. Este é um artigo de acesso aberto distribuído sob os termos da Licença Creative Commons CC BY.

Esta licença permite que outros distribuam, remixem, adaptem e criem a partir do seu trabalho, mesmo para fins comerciais, desde que the atribuam o devido crédito pela criação original. É a licença mais flexível de todas as licenças disponíveis. É recomendada para maximizar a disseminação e uso dos materiais licenciados. 